\title{
Is the frequency of having an eye test associated with socioeconomic factors? A national cross sectional study in British elderly
}

\author{
J C van der Pols, J R Thompson, C J Bates, A Prentice, S Finch
}

MRC Human

Nutrition Research, Cambridge $\mathrm{J}$ C van der Pols C J Bates

A Prentice

Leicester Royal Infirmary/University of Leicester,

Department of Ophthalmology

J R Thompson

Social and Community Planning Research,

London

S Finch

Correspondence to: Miss J C van der Pols, MRC Human Nutrition Research, Downham's Lane, Milton

Road, Cambridge CB4 1XJ.

Accepted for publication 24 May 1999

Table 1 Relation of having had an eye test during the year before the interview to socioeconomic factors

\begin{tabular}{|c|c|c|c|c|}
\hline Risk factor & $\begin{array}{l}\text { Number of } \\
\text { subjects }\end{array}$ & $\begin{array}{l}\text { Number (\%) of subjects } \\
\text { who had an eye test in } \\
\text { year before interview }\end{array}$ & $\begin{array}{l}\chi^{2} \text { test } \\
\text { (unadjusted) }\end{array}$ & $\begin{array}{l}\text { Adjusted odds } \\
\text { ratio }(95 \% C I)\end{array}$ \\
\hline \multicolumn{5}{|l|}{ Household Income $(£) \dagger$} \\
\hline$<4000$ & 222 & $111(50.0)$ & \multirow{4}{*}{$\mathrm{p}=0.003$} & $1.03(0.66,1.40)$ \\
\hline $4000-5999$ & 245 & $91(37.1)$ & & $0.61(0.25,0.97)$ \\
\hline 6000-9999 & 255 & $132(51.8)$ & & $1.09(0.74,1.44)$ \\
\hline$\geqslant 10000$ & 245 & $123(50.2)$ & & 1.00 reference \\
\hline \multicolumn{5}{|l|}{ Education level } \\
\hline Below secondary & 651 & $273(41.9)$ & \multirow[t]{2}{*}{$\mathrm{p}=0.017$} & $0.76(0.51,1.01)$ \\
\hline Secondary or higher & 430 & $212(49.3)$ & & 1.00 reference \\
\hline \multicolumn{5}{|l|}{ Receiving benefits $\ddagger$} \\
\hline Yes & 510 & $227(44.5)$ & \multirow[t]{2}{*}{$\mathrm{p}=0.894$} & $0.96(0.73,1.20)$ \\
\hline No & 686 & $308(44.9)$ & & 1.00 reference \\
\hline \multicolumn{5}{|l|}{ Social class household } \\
\hline Manuals & 631 & $259(41.0)$ & \multirow[t]{2}{*}{$\mathrm{p}=0.005$} & $0.75(0.52,0.98)$ \\
\hline Non-manual & 555 & $273(49.2)$ & & 1.00 reference \\
\hline
\end{tabular}

${ }^{\star}$ Adjusted for use of glasses for $3 \mathrm{~m}$ vision. †Annual household income before tax. ‡Any government benefits, not counting pensions. $₫$ Head of household in or retired from an occupation ascribed to Social Class III-manual, IV or V.
Since the government abolished free eye testing in 1989 there has been wide concern about the frequency of eye tests pursued by people over 65 years of age in Britain. ${ }^{12}$ Community based surveys have shown remediable visual impairment in a substantial proportion of the elderly population, which is mainly caused by uncorrected refractive errors, cataract, age related macular degeneration and glaucoma. ${ }^{34}$ Older people who had difficulties in performing activities of daily living because of their sight problems have repeatedly mentioned financial reasons as a barrier to attend eye care services. ${ }^{5}{ }^{6}$ The 1993 General Household Survey data suggested that social class may be a determinant of the eye test frequency. ${ }^{7}$ However, information on the frequency and determinants of eye testing in British elderly is very limited. We performed a cross sectional study in a national sample of British elderly to investigate the time since a last eye test and relations to socioeconomic factors.

\section{Methods and Results}

The National Diet and Nutrition Survey: People Aged 65 Years and Over (NDNS) recruited a representative sample of people aged 65 years or over from 80 different postcode sectors of mainland Britain. The sample included subjects from private households as well as from institutions such as nursing homes (not geriat-

(w)
which was arranged primarily for phlebotomy and anthropometric measurements.

Forty five per cent of the subjects (574 of 1275) reported having had their eyes tested within the year before the interview, $55 \%$ (701) had had their eyes tested more than a year ago and less than $1 \%(9)$ of the subjects reported that they never had their eyes tested. There were no significant differences (unadjusted $\chi^{2}$ test) in the time since the last eye test between men and women $(p=0.12)$, between subjects living in an institution and those living in the community $(p=0.70)$ or between different age groups $(\mathrm{p}=0.27)$. Subjects who were not using glasses for distance vision had had their eyes tested less often $(\mathrm{p}<0.0001)$ during the previous year (163 of 453) than subjects using glasses (411 of 822). 
Logistic regression analysis showed that subjects of manual social class or lower education level had less often had an eye test in the year before the interview than higher educated subjects or members of a non-manual household. This logistic regression analysis was corrected for a confounding difference in the use of glasses for distance vision between the different groups. Subjects from a household with a yearly income between $£ 4000$ and $£ 6000$ were less likely to have had a recent eye test than subjects from a household with an income over $£ 10000$ (table 1).

\section{Discussion}

Subjects with the lowest income have almost the same proportion of having had a recent eye test as those in the top two levels of income. This may be explained by the fact that subjects in the lowest income category probably qualify for a refund of the costs of an eye test through the means tested NHS Low Income Scheme. A direct relation between eye test frequency and receiving benefits was not shown in the current data (table 1), probably because receipt of any type of state benefits was included, whereas only receipt of certain types of benefits guarantees qualification for the NHS Low Income Scheme.

Limited awareness in older people of the importance of regular eye tests may be associated with the frequency of eye testing. ${ }^{9}$ Although attitude to eye testing was not investigated in our study, the lower frequency of recent eye tests in lower educated subjects could be an indicator of reduced awareness in that population group. The lower average household income in lower educated subjects $(\mathrm{p}<0.0001$ for trend) underlines the interdependence of these two factors.

Our data suggest that some socioeconomic obstacles may exist in older people to attend for an eye test. The announcement by the govern- ment that the NHS will provide free eye tests for pensioners from April 1999 may remove one of those obstacles. As the effectiveness of eye tests and visual screening in older people has been questioned, ${ }^{10}{ }^{11}$ more research is needed to identify the best public health measures to achieve a reduction in the prevalence of visual handicap in the elderly population.

We would like to thank Mark Reacher, Michael Whitelaw, Roger Whitehead and Tim Cole for their advice.

Funding: Miss van der Pols is receiving a research training grant from the European Commission DG-XII. The National Diet and Nutrition Survey of People Aged 65 Years and Over was funded jointly by the Ministry of Agriculture, Fisheries and Food and the Department of Health, and conducted by Social and Community Planning Research, in conjunction with the Medical Research Council's Dunn Nutrition Unit.

Conflicts of interest: none.

1 Rosenthal AR. High Street eye tests. Payments are deterring the elderly and blindness will increase. BMf 1990;300:695-

2 Wormald R, Fraser S, Bunce C. Time to look again at sight tests. BMF 1997;314:245.

3 Wormald RPL, Wright LA, Courtney P, et al. Visual problems in the elderly population and implications for problems in the elderly popula

4 Reidy A, Minassian DC, Vafidis G, et al. Prevalence of serious eye disease and visual impairment in a north London
population: population based, cross-sectional study. $B M \mathcal{F}$ 1998;316:1643-6

5 Harries U, Landes R, Popay J. Visual disability among older people: a case study assessing needs and examining services. F Public Health Med 1994;16:211-18.

6 Landes R, Popay J. "My sight is poor, but I'm getting on now": The health and social care needs of older people with vision problems. Health Soc Care 1993;1:325-35.

7 OPCS. General Household Survey 1993. London: HMSO, 1994

8 Finch S, Doyle W, Lowe C, et al. National Diet and Nutrition Survey: People aged 65 years and Over. Volume 1: Report of the Diet and Nutrition Survey. London: The Stationery Office, 1998.

9 Webster E, Wilson A, Barnes G. Eye tests in the elderly: factors associated with attendance and diagnostic yield in non-attenders. F $R$ Soc Med 1992;85:614-15.

10 Wang F, Tielsch JM, Ford DE, et al. Evaluation of screening schemes for eye disease in a primary care setting. Ophthalmic Epidemiol 1998;5:69-82

11 Smeeth L, Iliffe S. Effectiveness of screening older people for impaired vision in community setting: systematic review of evidence from randomised controlled trials. BMF 1998; 316:660-3 